\title{
Molecular Detection of Panton Valentine Leukocidin Toxin in Clinical Isolates of Staphylococcus aureus from Kiambu County, Kenya
}

\author{
Sani Iliya $\mathbb{D}^{1},{ }^{1}$ Jonathan Mwangi, ${ }^{2}$ Ronald Maathai, ${ }^{3}$ Mary Muriuki, ${ }^{4}$ \\ and Christopher Wainaina ${ }^{5}$ \\ ${ }^{1}$ Department of Biological Sciences, School of Pure and Applied Sciences, Mount Kenya University, Thika, Kenya \\ ${ }^{2}$ School of Pharmacy and Health Sciences, United States International University-Africa, Nairobi, Kenya \\ ${ }^{3}$ Department of Biochemistry, Mount Kenya University, Thika, Kenya \\ ${ }^{4}$ School of Pure and Applied Sciences, Mount Kenya University, Thika, Kenya \\ ${ }^{5}$ Hain Life Science East Africa Ltd., Nairobi, Kenya \\ Correspondence should be addressed to Sani Iliya; saniiliya32@gmail.com
}

Received 22 November 2019; Revised 7 July 2020; Accepted 12 August 2020; Published 27 August 2020

Academic Editor: Clemencia Chaves Lopez

Copyright (c) 2020 Sani Iliya et al. This is an open access article distributed under the Creative Commons Attribution License, which permits unrestricted use, distribution, and reproduction in any medium, provided the original work is properly cited.

Panton-Valentine leukocidin gene is produced by Staphylococcus aureus, and methicillin-resistant Staphylococcus aureus isolates as a pore-forming toxin is largely responsible for skin and soft tissue illnesses. MRSA produces PVL toxins through $l u k S$ and $l u k F$ proteins causing tissue necrosis by damaging membrane of the defense cells. Presence of PVL toxin was tested from the 54 S. aureus clinical isolates obtained from Thika and Kiambu Level 5 Hospitals, in Kiambu County, Kenya, by Geno Type ${ }^{\circledR}$ MRSA assay (Hain Life Science, Nehren, Germany). DNA was isolated from freshly harvested bacterial cultures by spin column using Geno Type DNA isolation kit. The detection of PVL toxins was performed by amplification of genomic DNA and by reverse hybridization that identifies PVL genes using Geno Type MRSA kit. Out of 138 samples that were collected from patients in Kiambu County, 54 S. aureus isolates were obtained, of which 14 (25.9\%; 95\% CI $=11.9-38.9)$ samples had PVL toxins. The isolates that were obtained from the female patients had a higher PVL toxin prevalence of $35.7 \%$, while the isolates collected from the male patients had a lower prevalence of $15.4 \%(P=0.09)$. The pediatrics department had the highest PVL gene prevalence compared to outpatient department and surgical units $(P=0.08)$. However, the age groups of patients and the hospital attended by patients showed no significant difference in terms of PVL gene prevalence $(P=0.26)$. Therefore, the patients' gender and hospital units were not significantly associated with PVL gene prevalence $(P=0.08)$. This study shows that PVL positive isolates occur in the sampled hospitals in the county and female as well as children must be taken into consideration among patients with wound infections when isolating $S$. aureus.

\section{Introduction}

Staphylococcus aureus is a main human pathogen causing community acquired and hospital acquired infections resulting to widespread morbidity and mortality. S. aureus causes surface colonization of skin and mucus membrane of healthy as well as carrier individuals as the significant predisposing factor for infection $[1,2]$. S. aureus is a substantial contributor to the overall burden on healthcare systems due to its high mortality rates of around $20-30 \%$ [3].
This burden is compounded by life-threatening complications, including infective endocarditis (IE) and other serious infections and complications that carry poor prognosis because of the anatomic site or the difficulty in reaching a timely diagnosis [4]. As part of its pathogenesis, S. aureus produces several virulence factors [5]. Panton-Valentine leukocidin (PVL) gene defined in 1932 by Panton and Valentine is a virulence factor produced by some strains of S. aureus, from two genes (lukS-PV and lukF-PV) encoding two proteins that causes leukocyte lysis and tissue necrosis 
[5-9]. PVL is associated with skin and soft tissue infection carried by both community-associated methicillin-susceptible $S$. aureus (CA-MSSA) and methicillin resistant $S$. aureus (CA-MRSA) and largely causes invasive as well as skin and soft tissue infections [10].

Panton-Valentine leukocidin is a pore-forming toxin largely responsible for skin and soft tissue illnesses [7]. There is significant variation in prevalence of PVL among $S$. aureus and methicillin-resistant $S$. aureus (MRSA) infections worldwide. Globally, prevalence of PVL toxin has been reported to increase across different countries such as Japan, USA, China, Germany, Egypt, Nigeria, and Kenya ranging from 12 to $90 \%$ [11-13]. Various studies have reported PVL prevalence with France at 5\%, Bangladesh at $14.3 \%$, Saudi Arabia at $8.1 \%$, UK at $8.1 \%$, Gambia at $72.9 \%$, Nigeria at $10.7 \%$, and Ghana at $75 \%[1,12,14]$. Data on PVL prevalence and its pathogenesis in $S$. aureus and MRSA disease have not been sufficiently shown to have common occurrence in Kenya $[15,16]$.

PVL, as a pore-forming gene, is linked to $S$. aureus pathogenesis where it causes tissue necrosis and leukocyte damage [7]. There is substantial distinction in PVL prevalence among $S$. aureus infections worldwide. In a study carried out in Iran by Goudarzi et al. [17], PVL producing S. aureus had prevalence of $29.2 \%$, where males had $58.6 \%$ and females had $41.4 \%$. PVL producing $S$. aureus strains has been found as a carriage in healthy person and from infections with prevalence of $1.4 \%$ and $38.5 \%$, respectively [8]. Molecular methods used in detecting PVL include a single polymerase chain reaction (PCR) to identify $l u k S-\mathrm{PV}$ and lukF-PV toxins [8]. Methods used to type PVL included multilocus sequence typing (MLST) as well as staphylococcus cassette chromosome mec (SCCmec) [18]. Other methods include PCR-based hybridization assay that detects PVL and $\gamma$-hemolysin genes of $S$. aureus using oligonucleotide probe [19]. In addition, Lina et al. [20] developed rapid and simple PVL and $\gamma$-hemolysin genes detection procedures for $S$. aureus to ease the previous methods that were cumbersome including oligonucleotide probes [19, 21-23]. Goudarzi et al. [17] analyzed the presence of lukS-PV and lukF-PV genes encoding compounds of PVL using PCR technique according to the procedure and protocol describe by Lina et al. [20]. This study focused on identifying PVL genes from both outpatient and inpatient attending pediatrics, male and female surgical units of Thika and Kiambu Level 5 Hospitals in Kiambu County, Kenya.

\section{Materials and Methods}

2.1. Study Design. This was a cross-sectional descriptive laboratory-based study involving inpatients and outpatients in two health facilities in Kenya, namely, Thika and Kiambu Level 5 Hospitals. The study was conducted between December 2017 and September 2018.

2.2. Study Area. Kiambu County is located within greater Nairobi, with its capital being Kiambu town and its largest town is Thika. The county is very cosmopolitan and serves to provide residences for most of Nairobi's workforce. Thika Level 5 Hospital is a 300-bed Government Hospital in the town of Thika and Kiambu Level 5 Hospital is a 289-bed government hospital located in Kiambu, East District, Kiambu County [15].

2.3. Study Population. The population of Kiambu County is mixed urban and rural. The patients in this study were residents in the county, admitted or seeking services in the 2 health facilities.

2.4. Ethical Considerations and Approval. This study was given clearance by Ethical Review Committee of Mount Kenya University (No. MKU/ERC/0467). Approval was also obtained from National Commission for Science and Technology and Innovation (NACOSTI) and Nairobi Kenya (No. NACOSTI/P/17/23223/18191). In addition, approval was provided by the Ministry of Interior, County Commissioner, Kiambu County (No. ED.12/1/VOL.V/125), the Department of Health Services, County Government of Kiambu (No. KIAMBU/HRDU/AUTHO/2017/11/25/Iliya S), and Kiambu and Thika Level 5 Hospitals medical superintendents/Thika Level 5 Hospital Research Committee (No. MOMS/TKA VOL III (368)). All samples obtained were held and kept under maximum confidentiality with consent of the subjects or their guardians to participate in the study. All patients or their guardians who participated in this study signed or thumb-printed an informed consent form. This study was conducted in accordance with the Declaration of Helsinki.

2.5. Inclusion Criteria. Inclusion criteria included presentation with wound or purulent discharge during inpatient or outpatient services, children and adults irrespective of age, ability to understand risks and benefits of the study, consent and agreement by patient or guardians (in case of children), signing or thumb-printing informed consent form, and patients residing in the county and seeking services in the 2 health facilities.

2.6. Exclusion Criteria. Patients (or the guardians) who declined to sign the informed consent form and patients not residing in the county and not admitted to the two health facilities were excluded.

2.7. Sample Collection. Sterile dry sterile cotton swabs were used in the collection of samples from infected sites. After collection of samples, the swabs were placed in sheaths and transported to the laboratory for inoculation.

2.8. Culture of Samples. The samples were inoculated into $5 \%$ sheep blood agar plates obtained commercially from Kenya Medical Research Institute (KEMRI), Nairobi, and incubated at $37.0^{\circ} \mathrm{C}$ for 24 hours. Single colony of cultures from sheep blood agar were inoculated into mannitol salt agar (KEMRI, Nairobi) plates and incubated at $37.0^{\circ} \mathrm{C}$ for 
24 hours before checking for fermentation of mannitol. All positive isolates from mannitol agar were subcultured into Mueller-Hinton agar (HiMedia, Mumbai, India) using a single discrete colony per plate (sample) and incubated at $37.0^{\circ} \mathrm{C}$ for 24 hours to obtain pure colonies. Identification of the bacterial isolates was carried out using standard microbiological procedures as was previously described including catalase test, coagulase, Gram staining, colony morphology, and fermentation of mannitol [24-26]. Pure cultures of $S$. aureus obtained were placed in tryptic soy broth (KEMRI, Nairobi, Kenya) and kept at $-80^{\circ} \mathrm{C}$ until needed for further analysis. S. aureus ATCC-25923 was used as control.

\subsection{Molecular Analysis}

2.9.1. Isolation and Purification of Genomic DNA from S. aureus. DNA was isolated from freshly harvested S. aureus cultures. Spin column DNA extraction procedure was used according to the technique developed by Hains Life Sciences using DNA isolation kit version 3.0 ${ }^{\circledR}$ (Hain Lifescience, Nehren, Germany) for extraction of genomic DNA from S. aureus isolates. Five (5) colony forming units (CFU) of $S$. aureus suspended in $150 \mu \mathrm{L}$ of molecular biology grade water were used to harvest enough DNA for molecular analysis. The bacterial suspension was incubated at $95^{\circ} \mathrm{C}$ for 15 minutes in a heating block. The suspension was incubated again in ultrasonic bath for 15 minutes. The suspension was spin down in tabletop centrifuge at $1500 \mathrm{rpm}$ for 5 minutes. To obtain supernatant solution of DNA, the spin filter membrane was washed with wash buffer to eliminate residual ethanol and DNA supernatant solution obtained after addition of elution buffer to the membrane. The DNA eluted was transferred to a new tube and stored at $-20.0^{\circ} \mathrm{C}$ until needed for further analysis. Agarose gel electrophoresis was used to check for the DNA integrity of the DNA extracted.

\subsubsection{Procedure for Panton-Valentine Leukocidin (PVL)} Toxins Detection. This was performed by amplification of genomic DNA followed by reverse hybridization that identifies PVL genes using Geno Type MRSA kit ${ }^{\circledR}$ (Hain Lifescience, Nehren, Germany) which was also designed to differentiate MRSA from $S$. aureus cultures. The kit contains a set of primers specific to staphylococcal cassette chromosome mec (SSCmec) types I, II, III, and IV including the community-acquired MRSA strain. The primers were designed to anneal to unique DNA regions and to generate amplicons that allowed identification of mecA and mecC that impart methicillin resistance as well as specific PVL gene fragments that give indication of CAMRSA acquired in the environment. Amplification procedure was carried out in Thermocycler, ABI 2720 (Applied Biosystems, Weiterstadt, Germany), according to the Geno Type MRSA ver. 3 technique. PCR master mix was prepared in $45 \mu \mathrm{L}$ amounts and $5 \mu \mathrm{L}$ DNA solution added in a separate working area to make the final volume of $50 \mu \mathrm{L}$. Detection of PVL was carried out by reverse hybridization using TwinCubator ${ }^{\circledR}$ (Hain Lifescience, Nehren, Germany) by means of a specific oligonucleotide probe targeting the SCCmec chromosomal cassette of MRSA that is immobilized on membrane strips. PCR amplicons hybridizes with probe during the detection process. Strips were added into individual troughs and hybridization carried out at $45^{\circ} \mathrm{C}$ for 30 minutes followed by two washings at $45^{\circ} \mathrm{C}$ for 30 minutes where amplicons that did not match were removed. Colorimetric identification of hybridized amplicons was performed by addition of streptavidin-conjugated alkaline phosphatase and the relevant substrate. The strips were air-dried and fixed on data sheet after final washings and read for the presence or absence of PVL genes. In comparison with standard/conventional method for PVL detection, this method achieved $100 \%$ correlation and shorter completion time $[27,28]$. It is a rapid, sensitive, and specific method for the detection of PVL [28]. Standard hybridization with oligonucleotide probe method for detection PVL takes 14 hours as compared to GenoType based assay with 4 hours before PCR completion [19]. The procedure was controlled with reference DNA from S. aureus strain N315.

Figure 1 shows the target area to be read on the strip.

2.10. Data Management and Statistical Analysis. Raw data was tabulated in Microsoft Excel, cleaned, and then exported to SPSS (Statistical Package for Social Science) software version 20.0 (IBM corporation, Armonk, New York, USA) for analysis. Values were expressed as percentages and frequencies. Categorical variables were analyzed using $\mathrm{Chi}$ square or Fisher exact tests (less than 5 expected counts in a cell) to test for the significant differences in their association. Differences were considered statistically significant when $P<0.05$.

\section{Results}

3.1. Prevalence of $S$. aureus. Out of the 138 specimens obtained in the two hospitals in Kiambu County, Kenya, 54 samples were $S$. aureus culture positive giving a prevalence of $39.1 \%$ (95\% CI $=30.1-46.4)$. Based on Hain Geno Type ${ }^{\circledR}$ assay, mecA impart methicillin resistance and the presence of bands on the target area confirmed the organism to be MRSA. Likewise, the presence of PVL genes gives indication of CA-MRSA strains that were acquired from the environment (Hain Lifescience leaflet and Geno Type manual). The presence of PVL in this assay, thus, serves to distinguish CA-MRSA from nosocomial MRSA. Among the 54 S. aureus isolates, $22(40.7 \%)$ were found to be MRSA based on our earlier MRSA detection method by cefoxitin-based susceptibility [29].

\subsection{Prevalence of Panton-Valentine Leukocidin Toxins.} Presence of PVL genes was tested from the 54 S. aureus isolates by Geno Type ${ }^{\circledR}$ MRSA molecular assay. Fourteen of the 54 isolates tested positive for the PVL gene giving a prevalence of $25.9 \%(14 / 54 ; 95 \% \mathrm{CI}=17.5-39.1)$ as shown in Table 1. In addition, fourteen isolates out of the 54 S. aureus were mecA positive, one of which had dual PVL and mecA 


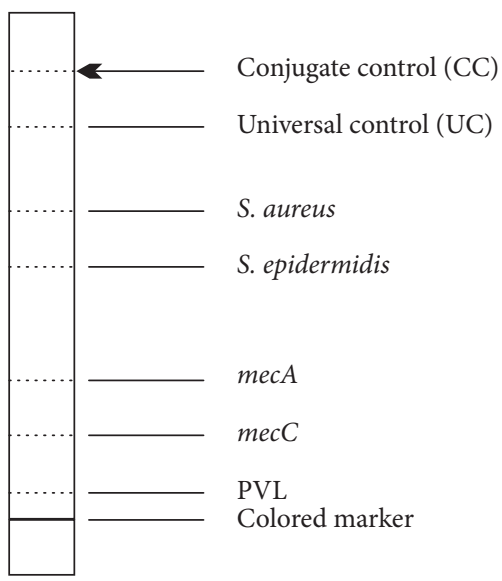

FIgURE 1: Geno Type MRSA ver. 3 target area Source: Hain Lifescience, Nehren, Germany.

TABle 1: Prevalence of the PVL gene.

\begin{tabular}{lccccc}
\hline Variable & $N$ & $\begin{array}{c}\text { PVL } \\
\text { present }\end{array}$ & $\begin{array}{c}\text { PVL } \\
\text { absent }\end{array}$ & Chi square & $P$ value \\
\hline Gender & & & & & \\
Male & 26 & $15.4 \%(4)$ & $84.6 \%(22)$ & 2.901 & 0.09 \\
Female & 28 & $35.7 \%(10)$ & $64.3 \%(18)$ & & \\
\hline Age & & & & & \\
$1-20$ & 20 & $40.0 \%(8)$ & $60.0 \%(12)$ & - & 0.26 \\
$21-40$ & 22 & $13.6 \%(3)$ & $86.4 \%(19)$ & & \\
$41-60$ & 8 & $25.0 \%(2)$ & $75.0 \%(6)$ & & \\
$61-80$ & 4 & $25.0 \%(1)$ & $75.0 \%(3)$ & & \\
\hline Hospital & & & & & \\
Kiambu & 37 & $32.4 \%(12)$ & $67.6 \%(25)$ & - & 0.18 \\
Thika & 17 & $11.8 \%(2)$ & $88.2 \%(14)$ & & \\
\hline Hospital unit & & & & & \\
OPD & 22 & $31.8 \%(7)$ & $68.2 \%(15)$ & - & \\
Surgical & 24 & $12.5 \%(3)$ & $87.5 \%(21)$ & & \\
Paediatric & 8 & $50.0 \%(4)$ & $50.0 \%(4)$ & & \\
\hline Total & $\mathbf{5 4}$ & $\mathbf{2 5 . 9 \% ( 1 4 )}$ & $\mathbf{7 4 . 1 \% ( 4 0 )}$ & & \\
\hline
\end{tabular}

Value expressed as percentage and frequencies (values in brackets). Chi square or Fisher's exact test was used to compute for associations between different groups. The $P$ values $<0.05$ were considered significant. OPD = outpatient department, $N=$ total number of samples; PVL $=$ Panton-Valentine leukocidin.

genes. More so, out of the 14 PVL positive $S$. aureus obtained, 9 were from the 22 MRSA (9/22) strains giving prevalence of $41 \%$ of PVL in MRSA strains.

3.2.1. Prevalence of PVL Gene by Gender. There was no significant association between the gender of the patients and the PVL gene prevalence among $S$. aureus positive isolates in Kiambu County, Kenya (Table 1; Chi square $=2.901 ; \mathrm{d} f=1 ; P=0.09)$. The isolates that were obtained from the female patients had a PVL gene prevalence of $35.7 \%(10 / 28)$, while the isolates collected from the male patients had a prevalence of $15.4 \%(4 / 26)$ as shown in Table 1.
3.2.2. PVL Gene Prevalence by Age Group in Years. There was no significant variation between the age groups of the patients in years and the prevalence of PVL gene in Kiambu County, Kenya (Table 1; Fisher's exact test; $P=0.26$ ). The age groups between 1 and 20, 21 to 40,41 to 60 , and 61 to 80 years old had a PVL gene prevalence of $40.0 \%(8 / 20), 13.6 \%(3 / 22), 25.0 \%(2 / 8)$, and $25.0 \%(1 / 4)$, respectively (Figure 2; Table 1 ).

3.2.3. PVL Gene Prevalence by Hospitals. There was no association between hospitals and PVL gene prevalence in Kiambu County, Kenya (Table 1; Fisher's exact test; $P=0.18)$. Kiambu hospital had a PVL gene prevalence of 32.4\% (12/37), while Thika hospital recorded a PVL gene prevalence of $11.8 \%(2 / 17)$ as shown in Figure 3 and Table 1.

3.2.4. PVL Gene Prevalence by Hospital Units. There was no significant association between hospital units and prevalence of PVL gene in Kiambu County, Kenya (Table 1; Fisher' exact test; $P=0.08$ ). The outpatient department (OPD), surgical and pediatric units, had a PVL gene prevalence of $31.8 \%(7 / 22), 12.4 \%(3 / 24)$, and $50 \%(4 / 8)$ as presented in Figure 4 and Table 1.

\section{Discussion}

The study has analyzed samples isolated from patients with purulent wounds for $S$. aureus in two very busy hospitals in Kiambu County, Kenya. The $S$. aureus positive samples were examined phenotypically through their growth in various media, Gram staining and confirmed by fermentation of mannitol, catalase, and coagulase tests. Out of 138 samples collected, 54 (39.1\%) were observed to have S. aureus. Thus, the number of positive $S$. aureus obtained is more than that of study done in 2014 from inpatients by Aiken et al. [15] at Thika Level 5 Hospital (which is one of this study's sites) with a prevalence of $8.9 \%$ and 2013 by Mbogolori et al. [30], in the neighboring Nairobi County, who observed a prevalence of $20 \%$.

Panton-Valentine leukocidin (PVL) toxin is linked to $S$. aureus infections where it causes tissue necrosis and leukocyte damage [7]. PVL is a pore-forming toxin largely responsible for skin and soft tissue illnesses [7]. In this study, we have tested the prevalence of PVL genes in 54 S. aureus positive clinical samples isolated from patients attending two major hospitals in Kiambu County, Kenya. Fourteen of the 54 isolates of $S$. aureus tested positive for the PVL gene which is a prevalence of $25.9 \%$. This is higher than the prevalence observed in Spanish study between 2005 and 2008 with prevalence of $3 \%$ [31] and $4.5 \%$ in Malaysia by Nastaly et al. [32], as well as $20 \%$ observed by Owrang et al. [33] in Iran and $24.1 \%$ prevalence reported in China by $\mathrm{Wu}$ et al. [34]. The PVL prevalence observed in this study is also comparatively higher than those reported in some other African countries with Thabit et al. [35] reporting 5.4\% prevalence in Egypt and prevalence of $10.7 \%$ in Nigeria by Orji et al. [13]. In a previous study in Kenya, Mbogolori et al. [30] observed a prevalence of $20 \%$ in Nairobi, while Aiken 


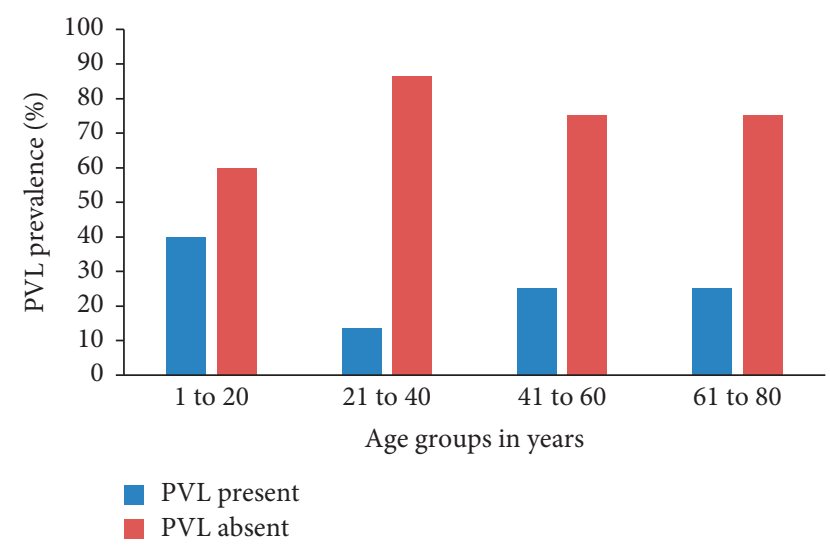

FIGURE 2: PVL gene prevalence by age groups in years.

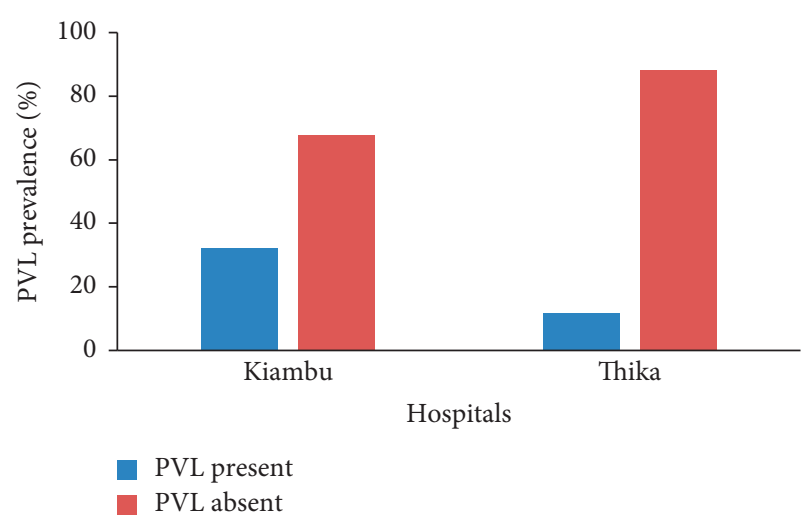

FIgURE 3: PVL gene prevalence by hospital.

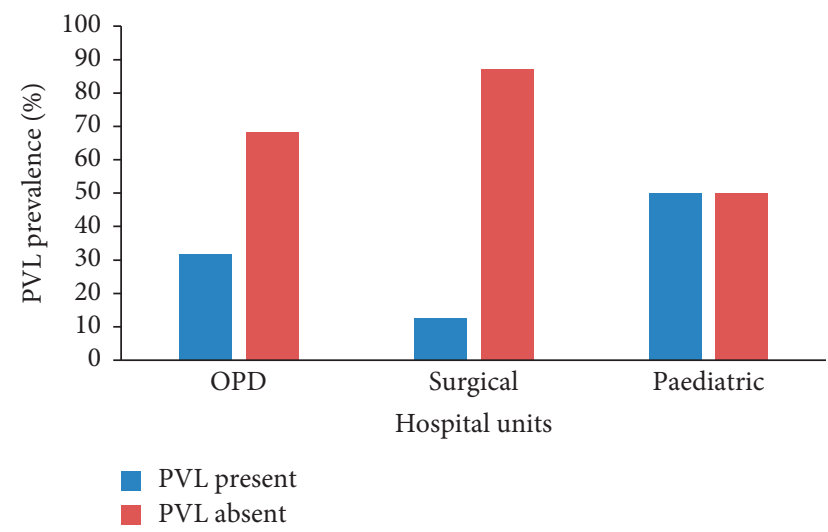

FIgURE 4: PVL gene prevalence by hospital units.

et al. [15] reported a prevalence of 7\% from MSSA in Thika. However, a higher prevalence of $40 \%$ was reported by Shittu et al. [36] in Nigeria.

The prevalence of MRSA that harbor PVL in this study is $41 \%$ which is higher than that observed in many countries such as $5.3 \%$ in Malaysia [37], 24\% in Bosnia and Herzegovina [38], 9.4\% in Zambia [39], 29\% in Libya [40], and 9\% in South Africa [40]. This prevalence is even higher than that reported in 2013 from the neighboring Nairobi region, although the earlier study analyzed isolates from patients with specific conditions [16]. However, the prevalence is lower than the $56.8 \%$ reported in Nepal [41], $57.1 \%$ in Gambia [1], and $73 \%$ in Uganda [40]. In our analysis, we have observed a significant association between MRSA and PVL with 9 out of the 14 (64\%; 95\% CI $=0.35-0.87)$ PVL positive isolates also being MRSA. This suggests a possible selective advantage for the $S$. aureus strains carrying genes that confer drug resistance and virulence. This would spell doom for the current efforts to control and manage infections with $S$. aureus because healthcare would be overwhelmed with more virulent but also more drug-resistant infections. A broader study is therefore needed to investigate this association between drug resistance and virulence in S. aureus to forestall a potential epidemic.

The association between the gender of the patients and the PVL gene prevalence showed no statistically significant relationship in this study (Fisher's exact test; $P=0.09$ ). The isolates that were obtained from female patients had PVL gene prevalence of $35.7 \%$ compared to those collected from the male patients with a prevalence of $15.4 \%$. Shallcross et al. [2] reported an association between gender and PVL-positive $S$. aureus carriage except that in their study males had the higher prevalence. The higher carriage of PVL in female as compared to male in our study could be due to the low sample size analyzed which could be explored further with higher sample size or bigger study.

In a study conducted by Darboe et al. [1] in Eritrea, PVL prevalence was high across all age groups and, therefore, age was not considered as a good predictor of toxins occurrence. Similarly, in this study, the age groups of patients showed no significant association with carriage of $S$. aureus positive for PVL genes $(P>0.26)$.

There was no association between hospitals and PVL gene prevalence in our study region (Fisher's exact test; $P=0.18$ ). Also, there was no observed significant association between hospital departments and prevalence of PVL gene-positive $S$. aureus (Fisher' exact test; $P=0.08$ ). The pediatrics unit had the highest PVL gene prevalence of $50.0 \%$, while surgical unit had the lowest PVL gene prevalence of $12.5 \%$. The high prevalence of PVL in hospital units at both facilities could be further explored in bigger study with higher sample size.

\section{Conclusion}

Methicillin-resistant Staphylococcus aureus presently poses a significant threat to public health mediations in both hospital and community settings globally. The results of our study have suggested that the prevalence of PVL carriage in $S$. aureus might be increasing compared to the levels observed in earlier studies in Kiambu County and the neighbouring Nairobi County. S. aureus PVL toxins could spread rapidly within the community leading to outbreak of community acquired infections. A greater concern, however, is the observed high PVL prevalence in MRSA S. aureus isolates. This needs to be further investigated in a broader study not only analyzing a bigger sample size but also incorporating patients with different health conditions. This 
will allow the exploration of this potential association of these two bacterial traits and what it portends for the management and control of $S$. aureus infections going forward.

The observed association of PVL-S. aureus carriage with gender and hospital departments, while not statistically significant in our study, needs to be further explored since they could impact the way infection control measures are practiced in different intrahospital settings. The overall results obtained in this study however need to be treated with caution. This is because our sample size is small and the participants were drawn from the geographical area served by the two hospitals sampled. The results therefore call for a bigger study, not just by increasing the sample size but by including other counties in the country to ascertain the findings. This would help in properly identifying the host and facility determinants that might predispose certain people to carry this more virulent form of the bacteria. However, it is imperative for the county's and health facilities authorities to take appropriate measures that include health education, surveillance, and screen all S. aureus isolates for PVL toxins so as to curtail outbreak of community as well as nosocomial infections. Hospital infection control strategy also needs to be strengthened in the county in order to prevent the spread of resistance.

\section{Abbreviations}

CA- Community-acquired methicillin resistant

MRSA: S. aureus

CA- Community-associated methicillin-susceptible

MSSA: $\quad S$. aureus

CFU: $\quad$ Colony forming units

IE: Infective endocarditis

MLST: Multilocus sequence typing

MRSA: Methicillin-resistant $S$. aureus

PCR: $\quad$ Polymerase chain reaction

PVL: Panton-Valentine leukocidin

S. aureus: Staphylococcus aureus

SCCmec: Staphylococcus cassette chromosome mec.

\section{Data Availability}

The data used to support the findings of this study are available from the corresponding author upon request.

\section{Conflicts of Interest}

The authors declare no conflicts of interest.

\section{Authors' Contributions}

All authors contributed equally in this work. SI, JM, RM, $\mathrm{MM}$, and CW designed the study. SI recruited the study populations and performed the laboratory analysis. JM, RM, and MM performed statistical analysis and wrote the manuscript. All authors read and approved the final manuscript.

\section{Acknowledgments}

The authors would like to thank the management and staff of male surgical, female surgical, children, and outpatient departments of Kiambu and Thika Level 5 Hospitals for their support and assistance. The authors also appreciate support given by Mr. Kamau N. Micha Medical Microbiology Laboratory, Mount Kenya University, Thika, Kenya, during isolation of the isolates.

\section{References}

[1] S. Darboe, S. Dobreniecki, S. Jarju et al., "Prevalence of Panton-Valentine leukocidin (PVL) and antimicrobial resistance in community-acquired clinical Staphylococcus aureus in an urban Gambian hospital: a 11-year period retrospective pilot study," Frontiers in Cellular and Infection Microbiology, vol. 9, p. 170, 2019.

[2] L. J. Shallcross, E. Fragaszy, A. M. Johnson, and A. C. Hayward, "The role of the Panton-Valentine leucocidin toxin in staphylococcal disease: a systematic review and metaanalysis," The Lancet Infectious Diseases, vol. 13, no. 1, pp. 43-54, 2013.

[3] G. E. Thwaites, J. D. Edgeworth, E. Gkrania-Klotsas et al., "Clinical management of Staphylococcus aureus bacteraemia," The Lancet Infectious Diseases, vol. 11, no. 3, pp. 208-222, 2011.

[4] W. V. Kern, "Management of Staphylococcus aureus bacteremia and endocarditis: progresses and challenges," Current Opinion in Infectious Diseases, vol. 23, no. 4, pp. 346-358, 2010.

[5] J. P. Rasigade, F. Laurent, G. Lina et al., "Global distribution and evolution of panton-alentine leukocidin-positive methicillin-susceptible Staphylococcus aureus, 1981-2007," The Journal of Infectious Diseases, vol. 201, no. 10, pp. 1589-1597, 2010.

[6] A. Holmes, M. Ganner, S. McGuane, T. L. Pitt, B. D. Cookson, and A. M. Kearns, "Staphylococcus aureus isolates carrying Panton-Valentine leucocidin genes in england and wales: frequency, characterization, and association with clinical disease," Journal of Clinical Microbiology, vol. 43, no. 5, pp. 2384-2390, 2005.

[7] K. Saeed, I. Gould, S. Esposito et al., "Panton-Valentine leukocidin-positive Staphylococcus aureus: a position statement from the international society of chemotherapy," International Journal of Antimicrobial Agents, vol. 51, no. 1, pp. 16-25, 2018.

[8] D. C. Melles, W. B. van Leeuwen, H. A. M. Boelens, J. K. Peeters, H. A. Verbrugh, and A. van Belkum, "PantonValentine leukocidin genes in Staphylococcus aureus," Emerging Infectious Diseases, vol. 12, no. 7, pp. 1174-1175, 2006.

[9] V. Neela, G. R. Ehsanollah, S. Zamberi, A. Van Belkum, and N. S. Mariana, "Prevalence of Panton-Valentine leukocidin genes among carriage and invasive Staphylococcus aureus isolates in Malaysia," International Journal of Infectious Diseases: IJID: Official Publication of the International Society for Infectious Diseases, vol. 13, no. 3, pp. e131-e132, 2009.

[10] B. B. Asiimwe, R. Baldan, A. Trovato, and D. M. Cirillo, "Molecular epidemiology of Panton-Valentine Leukocidinpositive community-acquired methicillin resistant Staphylococcus aureus isolates in pastoral communities of rural south 
western Uganda," BMC Infectious Diseases, vol. 17, no. 24, 2017.

[11] A. Karmakar, D. Jana, K. Dutta, P. Dua, and C. Ghosh, "Prevalence of Panton-Valentine leukocidin gene among community acquired Staphylococcus aureus: a real-time PCR study," Journal of Pathogens, vol. 2018, Article ID 4518541, 8 pages, 2018.

[12] O. O. Ayepola, N. A. Olasupo, L. O. Egwari, and F. Schaumburg, "Characterization of Panton-Valentine leukocidin-positive Staphylococcus aureus from skin and soft tissue infections and wounds in Nigeria: a cross-sectional study," F1000Research, vol. 7, p. 1155, 2018.

[13] O. L. Orji, B. O. Olayinka, B. Afolabi, and C. P. Ejikeugwu, "Molecular detection of panton-valentine leukocidin (PVL) toxins in clinical isolates of Staphylococcus aureus from Maitama district hospital, Abuja, Nigeria," Journal of Medical Microbiology and Diagnosis, vol. 5, no. 3, p. 240, 2016.

[14] E. Y. Garoy, Y. B. Gebreab, O. O. Achila et al., "Methicillinresistant Staphylococcus aureus (MRSA): prevalence and antimicrobial sensitivity pattern among patients-a multicenter study in Asmara, Eritrea," Canadian Journal of Infectious Diseases and Medical Microbiology, vol. 2019, Article ID 8321834, 9 pages, 2019.

[15] A. M. Aiken, I. M. Mutuku, A. J. Sabat et al., "Carriage of Staphylococcus aureus in Thika level 5 hospital, Kenya: a crosssectional study," Antimicrobial Resistance and Infection Control, vol. 3, no. 1, p. 22, 2014.

[16] E. K. Maina, C. Kiiyukia, C. N. Wamae, P. G. Waiyaki, and S. Kariuki, "Characterization of methicillin-resistant Staphylococcus aureus from skin and soft tissue infections in patients in Nairobi, Kenya," International Journal of Infectious Diseases, vol. 17, no. 2, pp. e115-e119, 2013.

[17] M. Goudarzi, M. Navidinia, E. Beiranvand, and H. Goudarzi, "Phenotypic and molecular characterization of methicillinresistant Staphylococcus aureus clones carrying the PantonValentine leukocidin genes disseminating in Iranian hospitals," Microbial Drug Resistance, vol. 24, no. 10, pp. 1543-1551, 2018.

[18] K. Zhang, J.-A. McClure, S. Elsayed, T. Louie, and J. M. Conly, "Novel multiplex PCR assay for characterization and concomitant subtyping of staphylococcal cassette chromosome mec types I to V in methicillin-resistant Staphylococcus aureus," Journal of Clinical Microbiology, vol. 43, no. 10, pp. 5026-5033, 2005.

[19] G. Prevost, P. Couppie, P. Prevost et al., "Epidemiological data on Staphylococcus aureus strains producing synergohymenotropic toxins," Journal of Medical Microbiology, vol. 42, no. 4, pp. 237-245, 2009.

[20] G. Lina, Y. Piémont, F. Godail-Gamot et al., "Involvement of Panton-Valentine leukocidin-producing Staphylococcus aureus in primary skin infections and pneumonia," Clinical Infectious Diseases: An Official Publication of the Infectious Diseases Society of America, vol. 29, no. 5, pp. 1128-1132, 1999.

[21] B. Cribier, G. Prévost, P. Couppie, V. Finck-Barbançon, E. Grosshans, and Y. Piémont, "Staphylococcus aureus leukocidin: a new virulence factor in cutaneous infections? An epidemiological and experimental study," Dermatology (Basel, Switzerland), vol. 185, no. 3, pp. 175-180, 1992.

[22] V. Finck-Barbancon, G. Prevost, and Y. Piemont, "Improved purification of leukocidin from Staphylococcus aureus and toxin distribution among hospital strains," Research in $\mathrm{Mi}$ crobiology, vol. 142, no. 1, pp. 75-85, 1991.
[23] M. Navidinia, M. Goudarzi, S. Rameshe et al., "Molecular characterization of resistance genes in MDR-ESKAPE pathogens," Journal of Pure and Applied Microbiology, vol. 11, no. 2, pp. 779-792, 2017.

[24] R. Amini, A. S. Abdulamir, B. P. Ling et al., "Isolation and identification of methicillin-resistant Staphylococcus aureus from keys of college students using different detection methods," British Biotechnology Journal, vol. 2, no. 1, pp. 13-25, 2012.

[25] M. Cheesbrough, "Biochemical tests to identify bacteria," in District Laboratory Practice in Tropical Countries, pp. 178-187, Cambridge University Press, Cambridge, UK, 2nd edition, 2000.

[26] D. P. Kateete, C. N. Kimani, F. A. Katabazi et al., "Identification of Staphylococcus aureus: DNase and Mannitol salt agar improve the efficiency of the tube coagulase test," Annals of Clinical Microbiology and Antimicrobials, vol. 9, no. 1, p. 23, 2010.

[27] M. Holfelder, U. Eigner, A. M. Turnwald et al., "Direct detection of methicillin-resistant Staphylococcus aureus in clinical specimens by a nucleic acid-based hybridisation assay," Clinical Microbiology and Infection: The Official Publication of the European Society of Clinical Microbiology and Infectious Diseases, vol. 12, no. 12, pp. 1163-1167, 2006.

[28] K. M. Otte, S. Jenner, and H. V. Wulffen, "Identification of methicillin-resistant Staphylococcus aureus (MRSA): comparison of a new molecular genetic test kit (GenoType MRSA) with standard diagnostic methods," Clinical laboratory, vol. 51, no. 7-8, pp. 389-393, 2005.

[29] S. Iliya, J. Mwangi, R. Maathai, and M. Muriuki, "Phenotypic analysis and antibiotic susceptibility of methicillin-resistant Staphylococcus aureus in Kiambu County, Kenya," The Journal of Infection in Developing Countries, vol. 14, no. 6, pp. 597-605, 2020.

[30] C. Mbogolori, A. Muigai, and S. Kariuki, "Detection and characterization of methicillin-resistant Staphylococcus aureus from toilet and classroom door handles in selected secondary school in Nairobi County," Open Journal in Medical Microbiology, vol. 3, no. 4, pp. 248-252, 2013.

[31] R. Blanco, A. Tristan, G. Ezpeleta et al., "Molecular epidemiology of Panton-Valentine Leukocidin-Positive Staphylococcus aureus in Spain: emergence of the USA300 clone in autochthonous population," Journal of Clinical Microbiology, vol. 49, no. 1, pp. 433-436, 2011.

[32] P. Nastaly, M. Grinholc, and K. P. Bielawski, "Molecular characteristics of community-associated methicillin-resistant Staphylococcus aureus strains for clinical medicine," Archives of Microbiology, vol. 192, no. 8, pp. 603-617, 2010.

[33] M. Owrang, A. Ranjkesh, Z. Salari et al., "Identification of Panton-Valentine leukocidin virulence gene in methicillin-resistant Staphylococcus aureus isolated from clinical specimens of burn patients in Zare hospitals of Sari, Iran," Journal of Acute Disease, vol. 9, no. 3, p. 121, 2020.

[34] S. Wu, J. Huang, F. Zhang et al., "Prevalence and characterization of food-related methicillin-resistant Staphylococcus aureus (MRSA) in China," Frontiers of Microbiology, vol. 10, p. 304, 2019.

[35] A. Thabit, A. Sadek, and E. Ahmed, "Molecular detection of Panton-Valentine leukocidin (PVL) and methicillin resistance in Staphylococcus aureus pathogen CA-MRSA, HA-MRSA, PVL genes, mecA gene," The Egyptian Journal of Medical Microbiology, vol. 26, no. 3, p. 10, 2018. 
[36] A. O. Shittu, K. Okon, S. Adesida et al., "Antibiotic resistance and molecular epidemiology of Staphylococcus aureus in Nigeria," BMC Microbiology, vol. 11, p. 92, 2011.

[37] P. S. Sit, C. S. J. Teh, N. Idris et al., "Prevalence of methicillinresistant Staphylococcus aureus (MRSA) infection and the molecular characteristics of MRSA bacteraemia over a twoyear period in a tertiary teaching hospital in Malaysia," BMC Infectious Diseases, vol. 17, no. 1, p. 274, 2017.

[38] V. Rebić, A. Budimir, M. Aljicević, S. Mahmutović Vranić, and D. Rebić, "Panton-Valentine leukocidin and staphylococcal cassette chromosome mec characterization of community acquired methicillin-resistant Staphylococcus aureus," Central European Journal of Public Health, vol. 27, pp. 58-63, 2019.

[39] M. T. Samutela, A. Kalonda, J. Mwansa et al., "Molecular characterisation of methicillin-resistant Staphylococcus aureus (MRSA) isolated at a large referral hospital in Zambia," Pan African Medical Journal, vol. 26, p. 108, 2017.

[40] S. M. Abdulgader, A. O. Shittu, M. P. Nicol, and M. Kaba, "Molecular epidemiology of Methicillin-resistant Staphylococcus aureus in Africa: a systematic review," Frontiers in Microbiology, vol. 6, p. 348, 2015.

[41] M. Dalman, S. A. Bhatta, N. Nagashreyaa et al., "Characterizing the molecular epidemiology of Staphylococcus aureus across and within fitness facility types," BMC Infectious Diseases, vol. 19, no. 69, 2019. 